\title{
A Novel Strategy for Inducing the Antitumor Effects of Triterpenoid Compounds: Blocking the Protumoral Functions of Tumor-Associated Macrophages via STAT3 Inhibition
}

\author{
Yukio Fujiwara, Motohiro Takeya, and Yoshihiro Komohara \\ Department of Cell Pathology, Graduate School of Medical Sciences, Faculty of Life Sciences, Kumamoto University, 1-1-1 Honjo, \\ Kumamoto 860-8556, Japan
}

Correspondence should be addressed to Yoshihiro Komohara; ycomo@kumamoto-u.ac.jp

Received 1 January 2014; Accepted 4 February 2014; Published 11 March 2014

Academic Editor: Masahisa Jinushi

Copyright (C) 2014 Yukio Fujiwara et al. This is an open access article distributed under the Creative Commons Attribution License, which permits unrestricted use, distribution, and reproduction in any medium, provided the original work is properly cited.

\begin{abstract}
There are many types of nontumor cells, including leukocytes, fibroblasts, and endothelial cells, in the tumor microenvironment. Among these cells, infiltrating macrophages have recently received attention as novel target cells due to their protumoral functions. Infiltrating macrophages are called tumor-associated macrophages (TAMs). TAMs polarized to the M2 phenotype are involved in tumor development and are associated with a poor clinical prognosis. Therefore, the regulation of TAM activation or M2 polarization is a new strategy for antitumor therapy. We screened natural compounds possessing an inhibitory effect on the M2 polarization of human macrophages. Among 200 purified natural compounds examined, corosolic acid (CA) and oleanolic acid (OA), both are categorized in triterpenoid compounds, inhibited macrophage polarization to M2 phenotype by suppressing STAT3 activation. CA and OA also directly inhibited tumor cell proliferation and sensitized tumor cells to anticancer drugs, such as adriamycin and cisplatin. The in vivo experiments showed that CA significantly suppressed subcutaneous tumor development and lung metastasis in a murine sarcoma model. The application of triterpenoid compounds, such as CA and OA, is a potential new anticancer therapy targeting macrophage activation, with synergistic effects with anticancer agents.
\end{abstract}

\section{Introduction}

Macrophages, first identified to be large phagocytes, play a critical role in innate and adaptive immunity by engulfing bacteria and other microbes and secreting several inflammatory molecules. Macrophages were first thought to be deleterious and inflammatory cells. However, recent studies have found that their functional roles are far more numerous. Macrophages are involved in remodeling/repair, neovascularization, atherosclerosis, and tumor development and are now considered multifunctional cells, more so than immune cells [1]. In tissue remodeling/repair processes, macrophages serve as key players for the resolution of inflammation and the restoration of the tissue integrity/function. The beneficial effects of macrophages are primarily due to the trophic factors they release in the environment, particularly those with effects on parenchymal cells. The wide range of active molecules secreted by macrophages likely explains their wide roles in tissue development, repair, and homeostasis demonstrated in various tissues [2].

Macrophages are broadly classified into classically activated macrophages (M1 macrophages) and alternatively activated macrophages (M2 macrophages), according to their functions. M1 macrophages are potent effecter cells that kill microorganisms and produce primarily proinflammatory cytokines, such as tumor necrosis factor $\alpha$ (TNF- $\alpha$ ), IL-6, and IL-12 [3]. In contrast, M2 macrophages reduce these inflammatory and adaptive Thl responses by producing anti-inflammatory factors (IL-10, TGF- $\beta$, and IL-1 receptor antagonist) and promoting angiogenesis, tissue remodeling, and repair [3]. M2 macrophages also exhibit a high expression of several receptors, including class A scavenger receptor (SR-A, CD204), mannose receptor (CD206), hemoglobin 
scavenger receptor (CD163), dectin-1, and DC-SIGN [4-8]. Macrophages are plastic cells, as they can switch from an activated M1 state back to an M2 state, and vice versa, upon the induction of specific signals [3].

Macrophages infiltrating in cancer tissues are referred to as tumor-associated macrophages (TAMs), which are closely involved in the development of the tumor microenvironment [9-11]. Heterogeneity of phenotypes is observed among TAMs in various malignant tumors, and a significant proportion of TAMs with the M2 phenotype is associated with a worse clinical prognosis and high grade of malignancy $[4,11-15]$.

We previously demonstrated CD163 to be a useful marker for detecting M2 cells on paraffin-embedded surgical specimens [16]. In several human malignant tumors, a proportion of CD163-positive M2 TAMs are closely involved in tumor cell proliferation and associated with a poor prognosis [1721]. CD163, a member of the scavenger receptor cysteinerich protein superfamily, is a receptor for the hemoglobinhaptoglobin ( $\mathrm{Hb}-\mathrm{Hp})$ complex, TNF-like weak inducer of apoptosis (TWEAK), and porcine reproductive and respiratory syndrome virus [22-25]. CD163 also binds bacteria and induces the production of proinflammatory cytokines [26]. It has been reported that binding of the $\mathrm{Hb}-\mathrm{Hp}$ complex to CD163-bearing cells elicits potent interleukin-10 secretion and the HO-1 expression $[27,28]$. These data indicate that CD163 is actively involved in the anti-inflammatory function of M2 macrophages, although the precise ligand receptor effector pathway has not yet been clarified. These observations suggest that macrophage differentiation (M2 polarization) is correlated with tumor development. Therefore, the regulation of macrophage activation is a potential new strategy for cancer immunotherapy.

Based on this background, we attempted to isolate natural compounds that suppress the M2 polarization of macrophages and identified two triterpenoid compounds, corosolic acid (CA), and oleanolic acid (OA), using newly established screening method. Notably, CA and OA not only inhibited M2 polarization but also suppressed tumor cell proliferation and sensitized tumor cells to anticancer drugs. The antitumor effects of CA were confirmed using a murine sarcoma model.

\section{Screening of Natural Compounds Inhibiting the CD163 Expression in Human Monocyte- Derived Macrophages (HMDMs)}

It is well known that enhancement of the CD163 expression, a useful cell surface marker of M2 phenotype, is accompanied by IL-10-induced M2 macrophage polarization. Recently, we established a Cell-ELISA system to detect the CD163 expression in macrophages in order to screen natural compounds regulating macrophage activation [29]. We first measured the effects of 200 natural compounds (selected compounds having famous bioactive structure such as flavonoid compounds, triterpenoid compounds, and steroid compounds from our natural compound library) on the IL-10-induced CD163 expression in human monocyte-derived macrophages
(HMDMs). Some natural compounds, including aucubin, CA, tigogenin, timosaponin AIII, neoaspidistrin, and OA, suppressed the CD163 expression (Figures 1(a) and 1(b)).

IL-10 secretion induced by stimulation with LPS is also used to evaluate M2 polarization. The tumor cell culture supernatant (TCS) of the U373 glioblastoma cell line induces the upregulation of IL-10 secretion from macrophages [29]. Among these compounds, $\mathrm{CA}$ and $\mathrm{OA}$, triterpenoid compounds, were found to significantly suppress IL-10 secretion from LPS-stimulated macrophages (Figure 1(c)), whereas CA and OA caused no morphological changes or cytotoxic effects in the HMDMs (Figure 1(d)). Therefore, we chose these triterpenoid compounds for further investigation (Figure 1(e)). Next, we measured the effects of CA and OA on the secretion of IL-12 and the expression of CD163 in HMDMs induced by TCS. Stimulation with TCS increased the CD163 expression (Figure 1(f)) and decreased IL-12 secretion (Figure 1(g)), a M1 phenotype marker, in the HMDMs. Under the employed assay conditions, CA and OA significantly suppressed the TCS-induced CD163 expression (Figure 1(f)) and enhanced the IL-12 secretion reduced by TCS treatment (Figure $1(\mathrm{~g})$ ). These data indicate that CA and OA change M2 polarization to $\mathrm{M} 1$ polarization in $\mathrm{HMDMs}$ and regulate macrophage activation.

\section{Effects of CA and OA on STAT3 Activation in the HMDMs}

It is well known that signal transducer and activator of transcription 3 (STAT3) is involved in the creation of the tumor microenvironment and tumor development due to its association with immunosuppression, angiogenesis, and cancer cell proliferation [30]. STAT3 signaling in macrophages is also involved in the regulation of immune responses in murine models [31, 32], and STAT3 activation is essential for macrophage differentiation toward the M2 phenotype [33]. Therefore, we next investigated the effects of CA and OA on IL-10- and TCS-induced STAT3 activation in HMDMs. As shown in Figure 1(h), STAT3 phosphorylation was increased in the HMDMs by stimulation with IL-10 and TCS. Under the employed assay conditions, CA and OA significantly inhibited the IL-10-induced STAT3 activation and suppressed the TCS-induced STAT3 activation in the HMDMs (Figure 1(h)). These results suggest that CA and OA change M2 polarization to M1 polarization in HMDMs by suppressing STAT3 activation.

\section{Effects of CA and OA on STAT3 Activation and Proliferation in Tumor Cells}

CA and OA have been reported to induce apoptosis in human cancer cells, such as cervix adenocarcinoma cells, gastric cancer cells, breast cancer cells, and hepatocellular carcinoma cells [34-39]. It is clear that activation of STAT3 is critically involved in tumorigenesis [40, 41]. Therefore, we next investigated the effects of CA and OA on STAT3 activation in tumor cells. As shown in Figure 2(a), STAT3 was consistently activated in U373 glioblastoma 


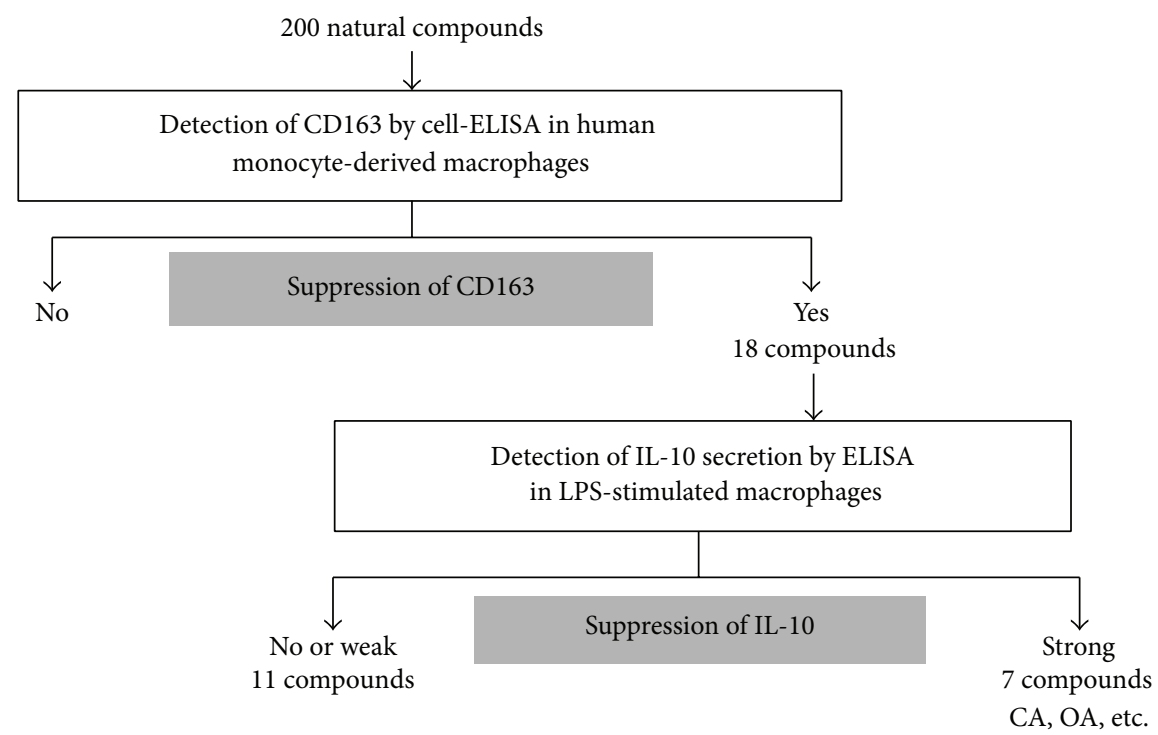

(a)

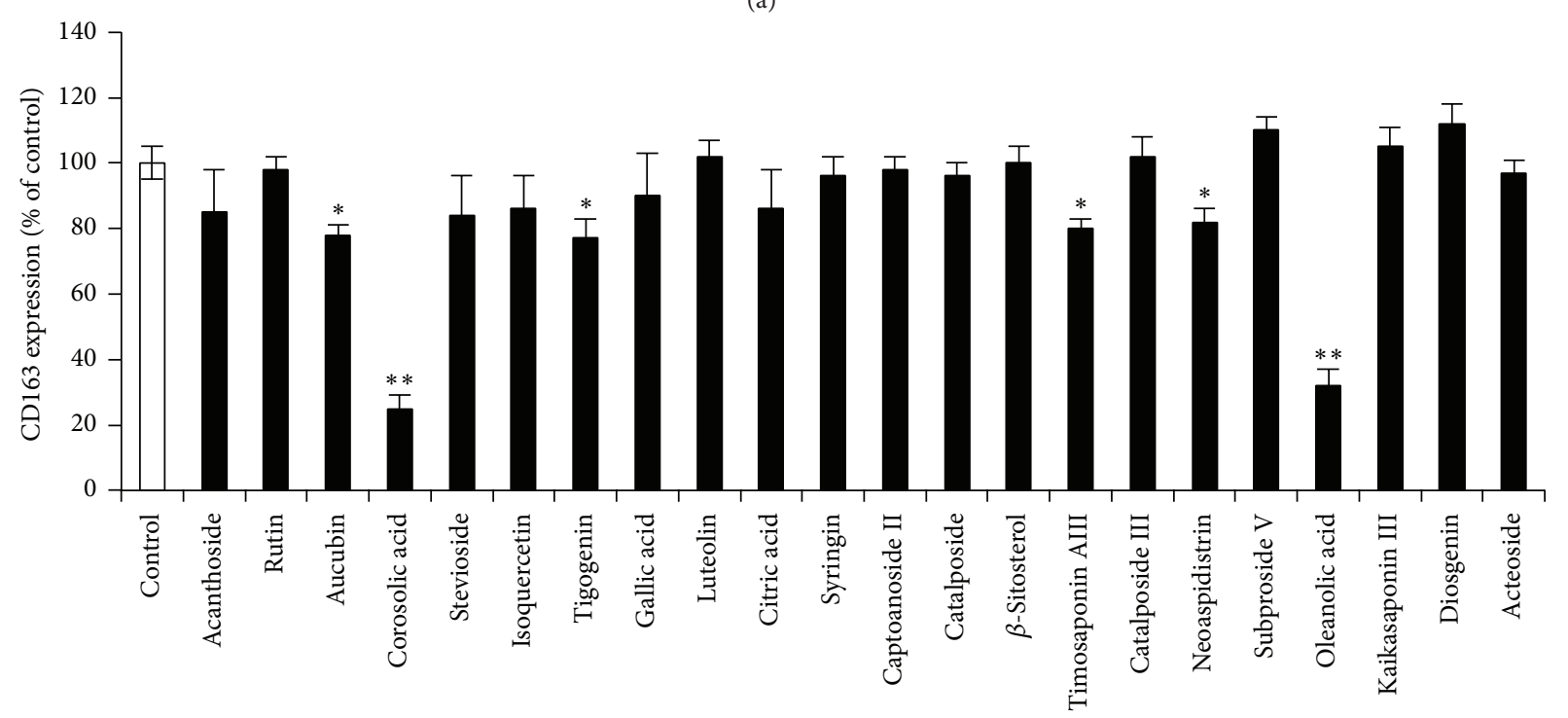

(b)
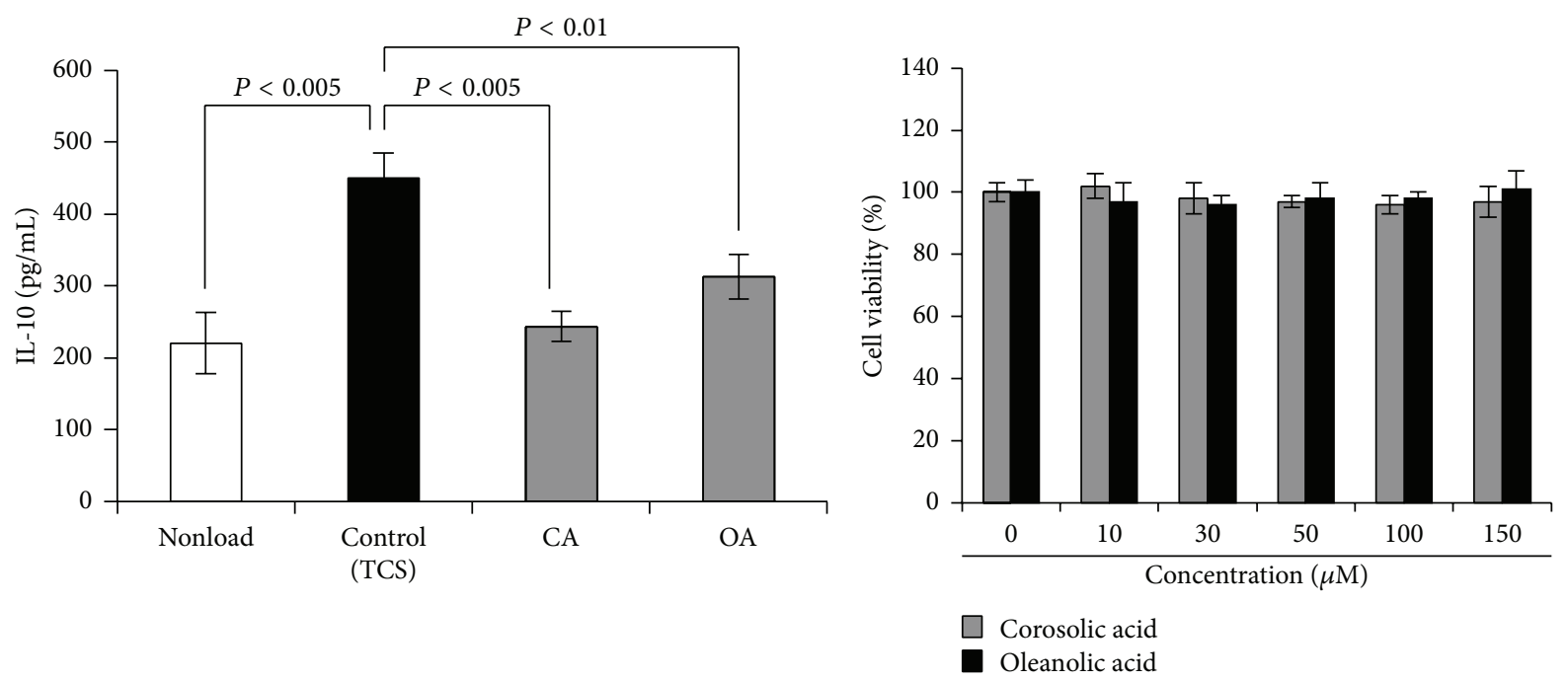

(c)

FIgure 1: Continued. 


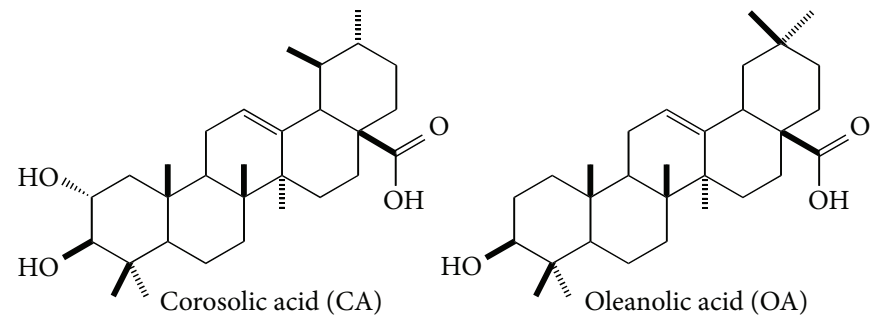

(e)

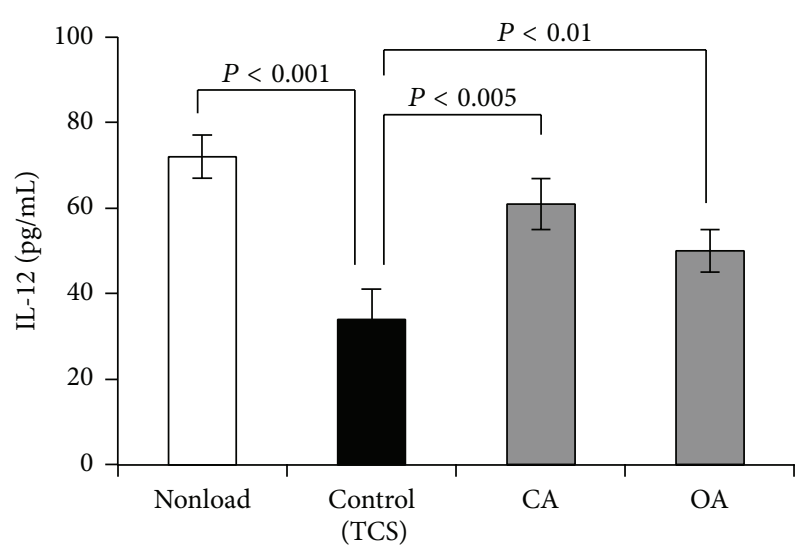

(g)

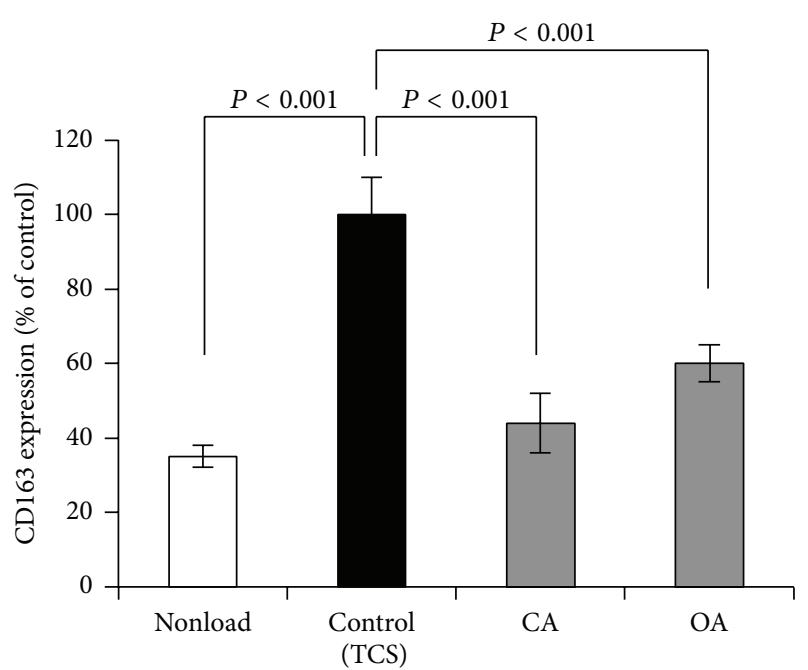

(f)

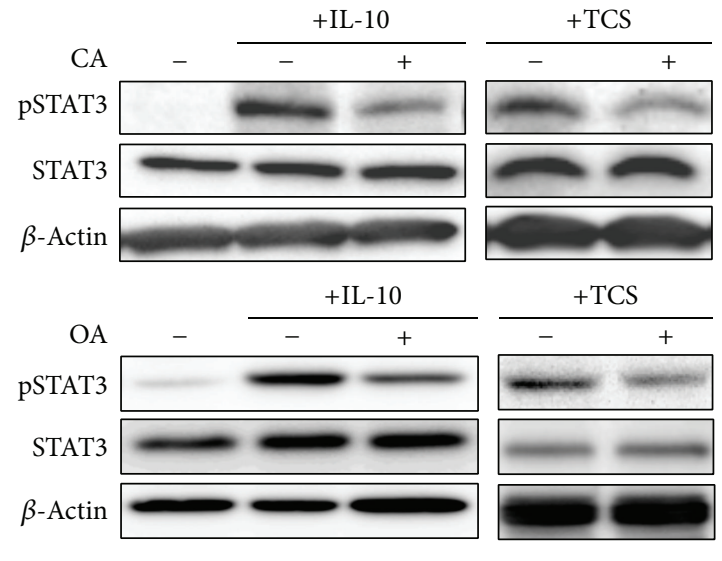

(h)

FIGURE 1: Effects of natural compounds on macrophage activation. A schematic drawing of the compound screening process (a). HMDMs $\left(5 \times 10^{4}\right.$ cells per well in a 96-well plate) were incubated with natural compounds $(30 \mu \mathrm{M})$ for 24 hours after treatment with IL-10 (20 nM) for two days, after which the CD163 expression was determined using Cell-ELISA (b). HMDMs $\left(5 \times 10^{4}\right.$ cells per well in a 96 -well plate) were stimulated with LPS $(100 \mathrm{ng} / \mathrm{mL})$ for 24 hours after incubation with $30 \mu \mathrm{M}$ of corosolic acid (CA) and $30 \mu \mathrm{M}$ of oleanolic acid (OA) for 24 hours in the presence of TCS, after which the level of IL-10 secretion was determined using ELISA (c). HMDMs $\left(5 \times 10^{4}\right.$ cells per well in a 96-well plate) were incubated with the indicated concentrations of corosolic acid (CA) and oleanolic acid (OA) for 24 hours, after which the cell viability was determined using a WST-8 assay (d). Chemical structures of corosolic acid (CA) and oleanolic acid (OA) (e). HMDMs $\left(5 \times 10^{4}\right.$ cells per well in a 96-well plate) were incubated with $30 \mu \mathrm{M}$ of corosolic acid (CA) and $30 \mu \mathrm{M}$ of oleanolic acid (OA) for 24 hours after treatment with U373 glioblastoma-derived tumor cell supernatant (TCS) for two days, after which the CD163 expression was determined using Cell-ELISA (f). HMDMs $\left(5 \times 10^{4}\right.$ cells per well in a 96-well plate) were stimulated with LPS (100 ng/mL) for $24 \mathrm{hours}$ after incubation with $30 \mu \mathrm{M}$ of corosolic acid (CA) and $30 \mu \mathrm{M}$ of oleanolic acid (OA) for 24 hours in the presence of TCS, after which the level of IL-12 secretion was determined using ELISA (g). HMDMs were incubated with $30 \mu \mathrm{M}$ of corosolic acid (CA) or oleanolic acid (OA) for three hours after treatment with IL-10 $(20 \mathrm{nM})$ or TCS for 24 hours, after which the levels of phosphorylated STAT3, STAT3, and $\beta$-actin were determined using a Western blot analysis (h). The data are presented as the mean $\pm \mathrm{SD} .{ }^{*} P<0.01,{ }^{* *} P<0.001$ versus control.

cells. Under the assay conditions, CA and OA significantly inhibited STAT3 activation (Figure 2(a)). Furthermore, CA and OA significantly suppressed the proliferation of U373, Saos2 (osteosarcoma), HSOS-1 (osteosarcoma), and LM8 (murine sarcoma) in a dose-dependent manner (Figure 2(b)). Similar antitumor effects were observed in other malignant tumor cells, including ovarian cancer cells (data not shown), whereas these compounds did not affect cell survival in the HMDMs (Figure $1(\mathrm{~d})$ ), thus suggesting that effective concentrations of these compounds $(30 \mu \mathrm{M} \sim$ $100 \mu \mathrm{M})$ do not affect normal cell viability with respect to tumor cell death. These data indicate that CA and OA suppress tumor cell proliferation by inhibiting STAT3 activation. 

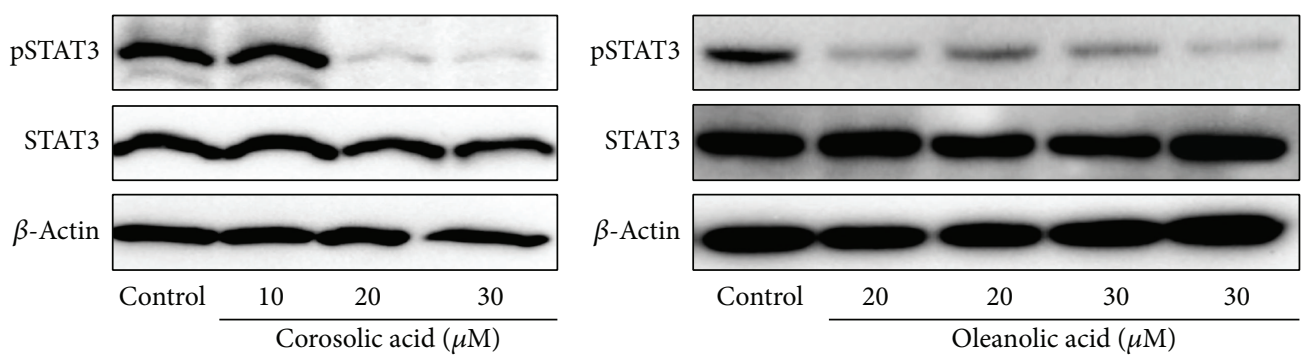

(a)
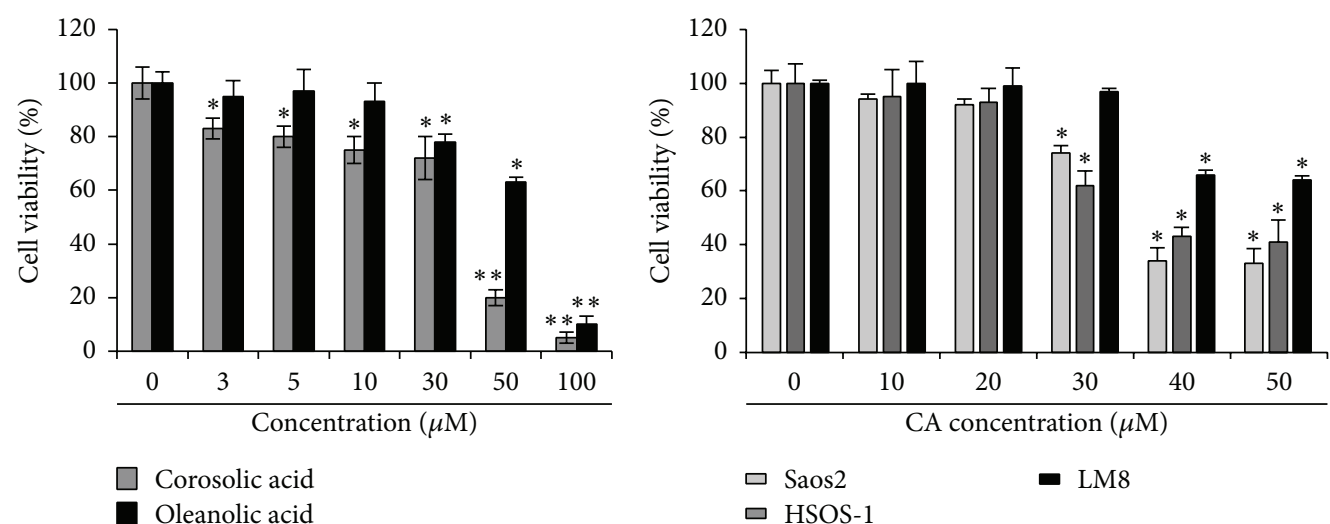

(b)

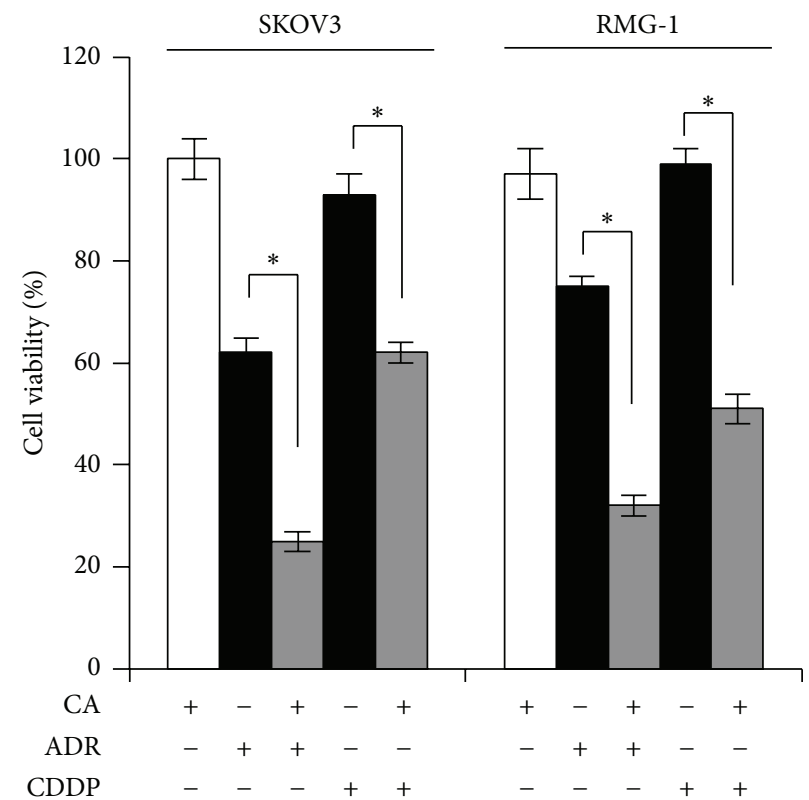

(c)

FIGURE 2: Effects of corosolic acid and oleanolic acid on STAT3 activation and cell proliferation in the tumor cells. U373 cells were incubated with the indicated concentrations of corosolic acid or oleanolic acid for three hours, after which the phosphorylated STAT3, STAT3, and $\beta$-actin expression was determined using a Western blot analysis (a). Glioblastoma cells (U373 cells) and osteosarcoma cells (Saos2 cells, HSOS-1 cells, and LM8 cells) were incubated with the indicated concentrations of corosolic acid and oleanolic acid for 24 hours, after which the degree of cell proliferation was determined using a WST- 8 assay (b). Ovarian carcinoma cells, SKOV3 and RMG- 1 cells, were incubated with $10 \mu \mathrm{M}$ of anticancer drugs (ADR: adriamycin; CDDP: cisplatin) during incubation with or without corosolic acid ( $20 \mu \mathrm{M})$ for 24 hours, after which the cell viability was determined using a WST- 8 assay (c). The data are presented as the mean \pm SD. ${ }^{*} P<0.05$, ${ }^{* *} P<0.001$ versus control. 


\section{Synergistic Antitumor Effects of CA and Chemotherapeutic Agents}

We next measured the combined effects of CA and chemotherapeutic agents on tumor cell proliferation using tumor cell lines. In this experiment, CA was used at a concentration of $20 \mu \mathrm{M}$, as this dose has been shown to suppress STAT3 activation but not inhibit tumor cell viability (Figure 2(b)). Consequently, CA significantly increased the antitumor effects of adriamycin (ADR) and cisplatin (CDDP) in ovarian cancer cells (Figure 2(c)). Similar results were observed in osteosarcoma and glioblastoma cells (data not shown). These data suggest that CA suppresses tumor proliferation and is a potential candidate agent for enhancing anticancer chemotherapeutic agents in several types of tumor cells.

\section{CA Suppresses Subcutaneous Tumor Development and Lung Metastasis}

In the present study, the antitumor effects of CA were tested in a mouse sarcoma model. CA was administered orally before and after subcutaneous implantation with LM8 cells in $\mathrm{C} 3 \mathrm{H}$ mice (Figure $3(\mathrm{a})$ ). It is previously reported that CA was detected in blood after oral administration of CA to animal model [42]. On day 21 after tumor implantation, subcutaneous tumor development and small metastatic lesions were detected in all control mice. The results of the experiment showed that CA administration significantly suppressed subcutaneous tumor development (Figure 3(b)). In addition, CA significantly suppressed lung metastasis (Figure 3(b)). Furthermore, STAT3 activation in developed tumor cells was decreased by the administration of CA (Figure 3(c)), thus suggesting that CA suppresses STAT3 activation in both in vitro and in vivo models. On the other hand, PCNA labeling was not affected by treatment with CA (data not shown). Infiltration of immune cells and the presence of angiogenesis were evaluated using immunostaining. The results of immunostaining showed that the levels of $\mathrm{CD}^{+}$ and $\mathrm{CD}^{+}$lymphocytes in the subcutaneous tumor tissues were increased by the administration of CA (Figure 3(d)). There were no significant differences in the number of $\mathrm{CD}^{+} 8^{+}$ TAMs, CD $204^{+}$TAMs, or CD $31^{+}$vessels (data not shown). These data suggest that CA impairs tumor development and lung metastasis by activating antitumor immunity.

Inhibitory effect of CD163 expression was not investigated in this tumor model, because no $\mathrm{CD}_{163}{ }^{+}$cells were detected in the tumor tissues of either the vehicle or CA administration group (data not shown). In our observation, the born marrow-derived macrophages hardly express CD163 at all (unpublished data). TAMs in murine tumor models are mainly from bone marrow and this might be a reason that no CD163 expression is detected in TAMs in murine tumor model.

Recent studies have demonstrated that myeloid cells are associated with systemic immune suppression in tumorbearing hosts. In particular, myeloid cells positive for $\mathrm{Gr}-1$ and CD11b in tumor-bearing mice are called myeloid-derived suppressor cells (MDSCs) due to their suppressive effects on T-cell activation. In murine tumor models, MDSCs in tumor tissues, as well as the spleen, liver, and bone marrow, have become the focus of research in recent years due to their immunosuppressive functions [43-45]. Since MDSCs and TAMs are considered to be from the same lineage, we hypothesized that CA also inhibits the immunosuppressive function of MDSCs. Initially, the number of MDSCs was evaluated using flow cytometry; however, no significant changes were observed between the control and CA-treated groups in either the spleen or bone marrow (data not shown). In order to test the immunosuppressive activity of MDSCs by means of an ex vivo analysis, $\mathrm{CD} 4^{+}$or $\mathrm{CD}^{+}$lymphocytes isolated from naive $\mathrm{C} 3 \mathrm{H}$ mice were cocultured with MDSCs purified from the spleens of tumor-bearing or control mice. The MDSCs derived from the tumor-bearing mice significantly inhibited lymphocyte proliferation (Figure 3(e)). However, this suppressive effect was not observed among the MDSCs derived from the spleens of the tumor-bearing mice treated with CA (Figure 3(e)). These data indicate that although CA did not affect the number of MDSCs, it reversed the immunosuppressive activity of these cells. In order to investigate which immunosuppressive molecules are changed by CA administration, the mRNA expression of various MDSCs -related molecules was evaluated using real-time PCR. The results showed that the administration of $\mathrm{CA}$ resulted in the downregulation of cyclooxygenase-2 and CCL2 in the MDSCs (Figure 3(f)). Furthermore, CA treatment appeared to inhibit STAT3 activation in splenic MDSCs in the tumorbearing mice (data not shown). These results suggest that CA activates antitumor immune reactions by inhibiting the immunosuppressive activity of MDSCs.

\section{Antitumor Effects of Ursolic Acid (UA)}

Although ursolic acid (UA) was not contained in the selected 200 purified natural compounds, UA is a well-known natural compound belonging to the triterpenoid family and there are many reports regarding the antitumor effects of UA [4652]. It has also been reported that UA inhibits tumor cell proliferation in several tumor cells, such as breast cancer cells [46], gastric cancer cells [47], colon cancer cells [48], skin cancer cells [49], leukemia cells [50], lung cancer cells [51], and pancreatic cancer cells [52]. Furthermore, it has also been demonstrated that UA suppresses the growth of colon cancer cells by targeting STAT3 [48], whereas the effects of UA on macrophage activation are unknown. However, the fact that UA abrogates STAT3 activation suggests that UA impairs tumor development not only due to its direct cytotoxicity to tumor cells but also by inhibiting the protumoral functions of TAMs and MDSCs.

\section{Tumor-Associated Macrophages as Potential Targets of Existing Medicines}

There are several lines of evidence supporting the potential for targeting TAMs using existing medicines [53-55]. Bisphosphonates (BPs), such as zoledronic acid, which are 


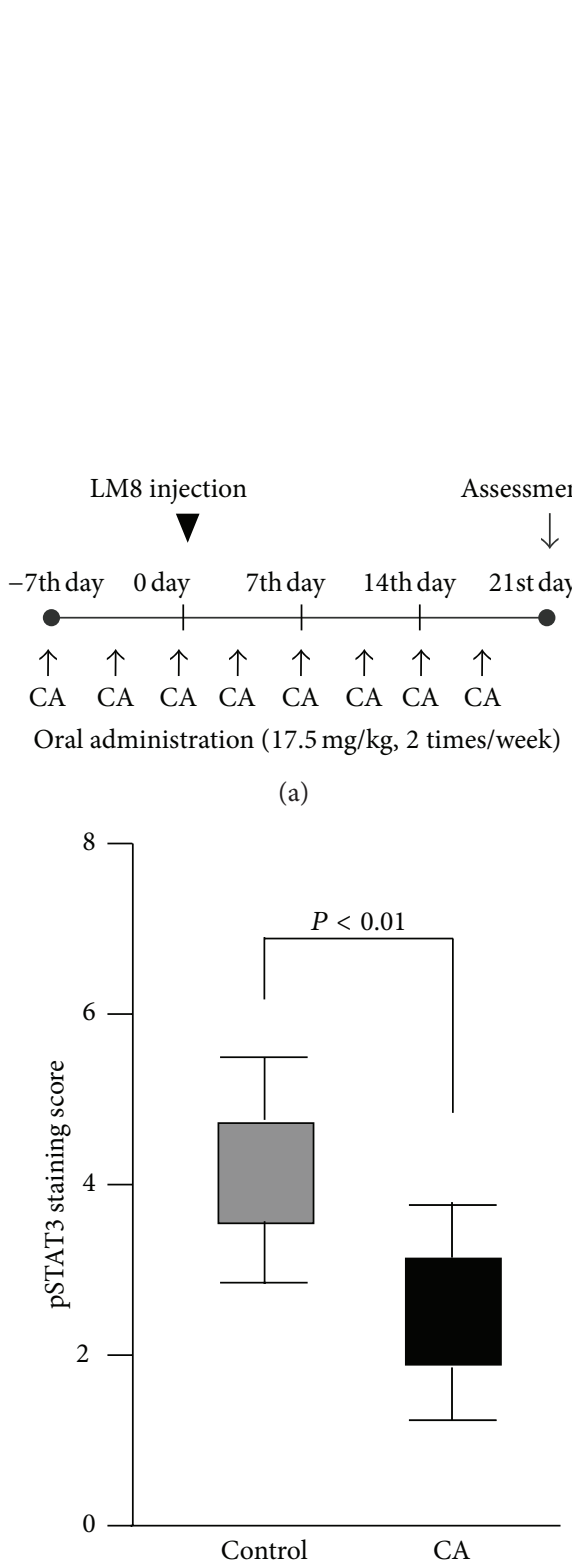

(c)

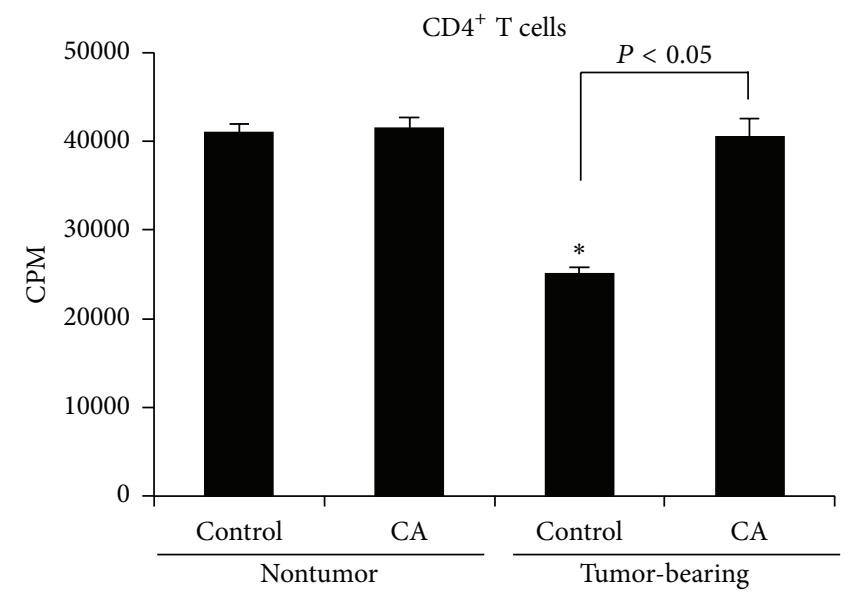

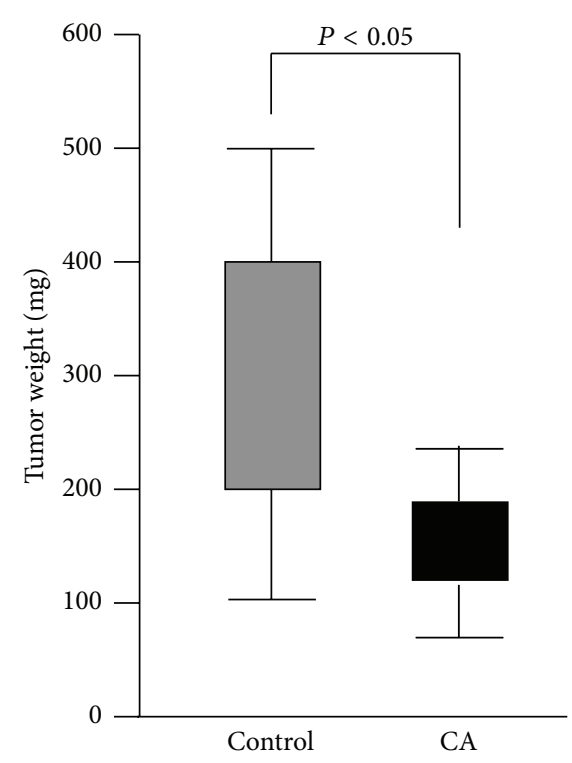

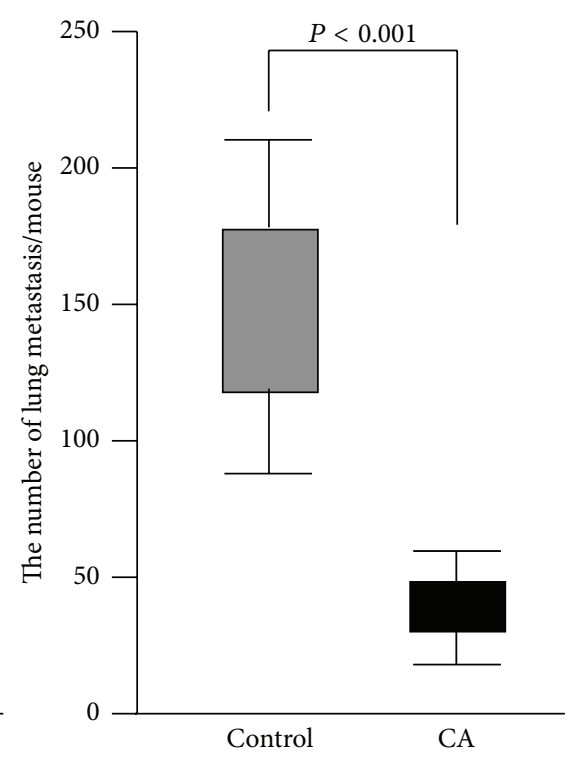

(b)
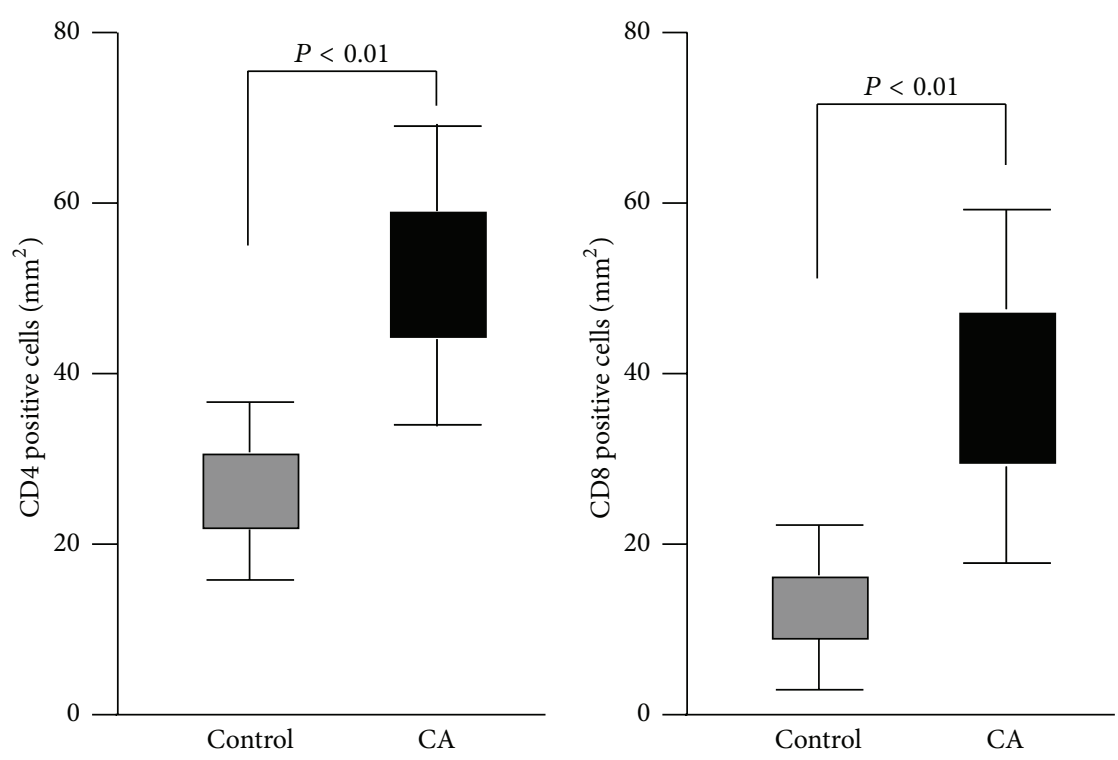

(d)

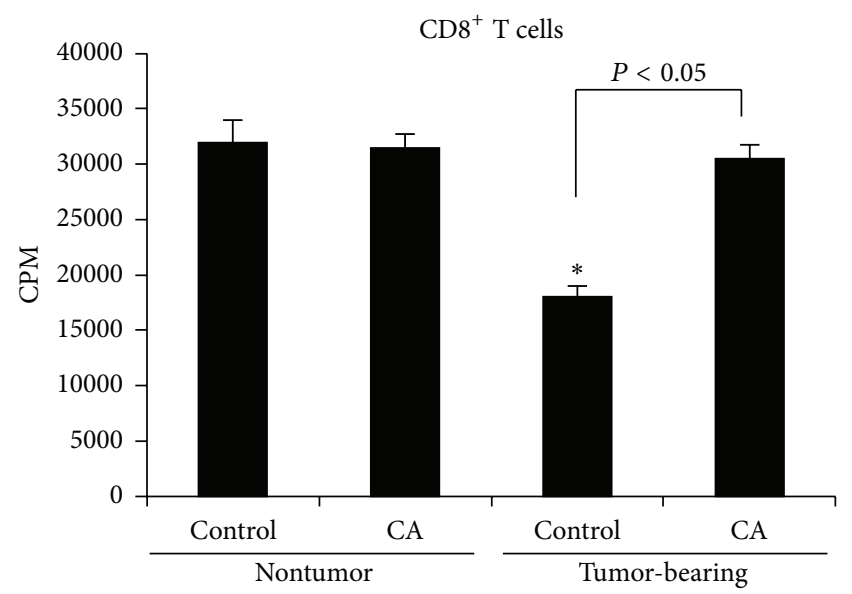

(e)

Figure 3: Continued. 


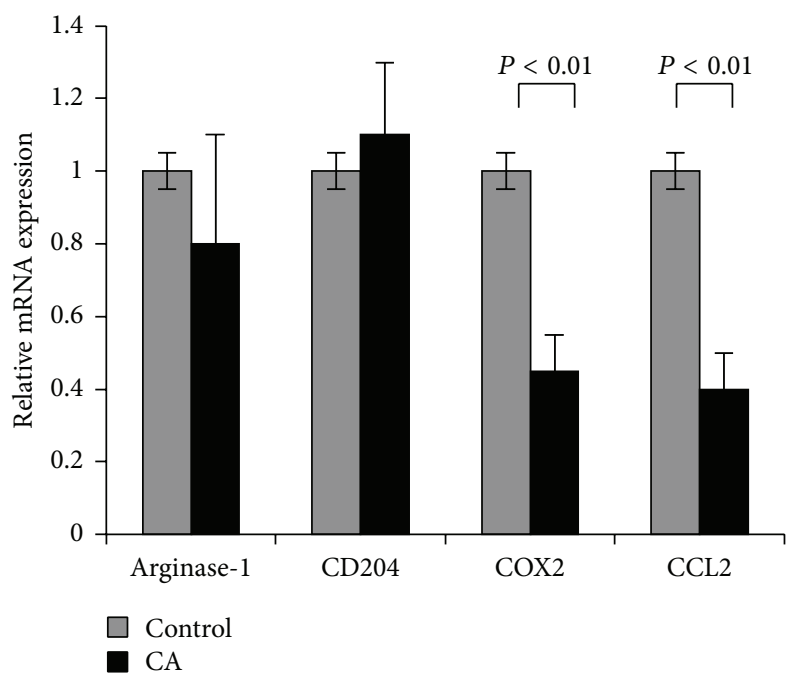

(f)

FIGURE 3: Antitumor effects of corosolic acid in the LM8-injected mice model. Protocol for administering corosolic acid (CA) and implanting LM8 (a). Effects of corosolic acid (CA) on subcutaneous tumor development and lung metastasis (b). The degree of STAT3 activation in the subcutaneous tumor tissues was evaluated using immunostaining (c). The number of CD $4^{+}$lymphocytes and $\mathrm{CD} 8^{+}$lymphocytes in the subcutaneous tumor tissues was evaluated using immunostaining (d). Inhibitory effects of corosolic acid on the MDSC-induced immunosuppressive activity in CD4 and CD8 T cells (e). MDSCs were isolated from tumor-bearing mice treated with or without corosolic acid, and the mRNA expression was examined using real-time PCR (f). The data are presented as the mean \pm SD. ${ }^{*} P<0.05$ versus control.

antiresorptive agents approved for the treatment of skeletal complications associated with metastatic breast and prostate cancer, decrease tumor growth and lung metastasis, while zoledronic acid reverses the polarity of TAMs from M2 to M1, thus suggesting that TAMs are potential targets of bisphosphonate therapy [55]. Cyclosporine A, an immunosuppressive agent, reduces tumor growth and inhibits the alternative activations of tumor-infiltrating microglia/macrophages in a glioma model, suggesting that blocking the infiltration of microglia/macrophages and their proinvasive functions is a potential novel therapeutic strategy in patients with glioma [53]. Furthermore, trabectedin, an anticancer drug, suppresses both tumor development and TAM activation in cases of myxoid liposarcoma [54]. These reports demonstrate that the regulation of macrophage activation is a potential target for anticancer therapy.

\section{Conclusion}

STAT3 is associated with tumor progression in many malignant tumors. STAT3 is considered to be an important target molecule for anticancer therapy, and many researchers have thus far reported the importance of various STAT3 inhibitors in the setting of anticancer therapy [56]. Natural compounds, such as $\mathrm{CA}$ and OA, exert inhibitory effects on STAT3 activation in macrophages, MDSCs, and tumor cells $[29,57,58]$. In the present study, we revealed that those compounds inhibit tumor proliferation and differentiation of macrophages toward M2 phenotype via inhibiting STAT3 activation, whereas inhibitory mechanism of those compounds on MDSCs function has not been unclear. Furthermore, our findings indicate that these compounds may

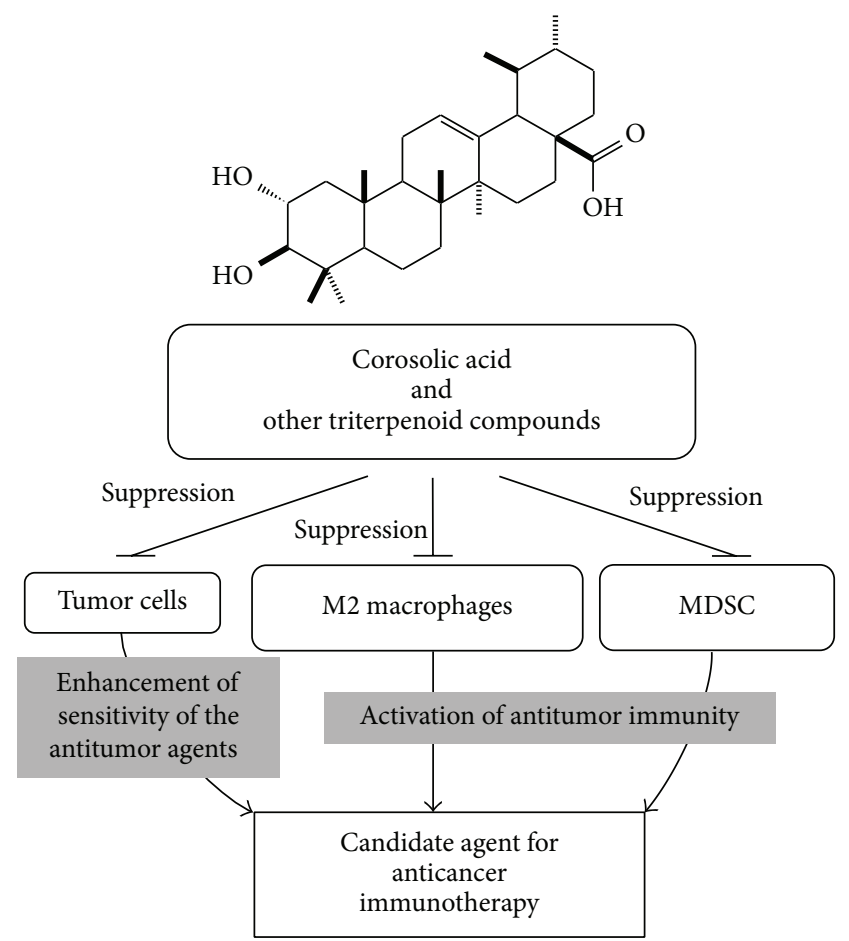

Figure 4: Possible mechanism underlying the inhibitory effects of corosolic acid and other triterpenoid compounds on tumor proliferation.

be useful in anticancer therapy by targeting the immunosuppressive activity of MDSCs and TAMs via synergistic effects with anticancer agents (Figure 4). Triterpenoid compounds regulating the activation of myeloid cells, including MDSCs 
and TAMs, are potential candidate agents for anticancer therapy.

\section{Conflict of Interests}

The authors declare that there is no conflict of interests regarding the publication of this paper.

\section{Acknowledgments}

The authors thank Dr. Koji Ohnishi, Dr. Hasita Horlad, Dr. Kenichi Takemura, Dr. Kiyomi Takaishi, Dr. Daisuke Shiraishi, Dr. Junko Nakao, Mr. Takenobu Nakagawa, Mrs. Emi Kiyota, Mr. Osamu Nakamura, and Ms. Yui Hayashida for their support and technical assistance. This study was supported in part by JSPS Grants-in-Aid for Scientific Research (Grant nos. B20390113, 2179388, and 23790747).

\section{References}

[1] J. A. Stefater, S. Ren, R. A. Lang, and J. S. Duffield, "Metchnikoff's policemen: macrophages in development, homeostasis and regeneration," Trends in Molecular Medicine, vol. 17, no. 12, pp. 743-752, 2011.

[2] J. W. Pollard, "Trophic macrophages in development and disease," Nature Reviews Immunology, vol. 9, no. 4, pp. 259-270, 2009.

[3] F. Porcheray, S. Viaud, A.-C. Rimaniol et al., "Macrophage activation switching: an asset for the resolution of inflammation," Clinical and Experimental Immunology, vol. 142, no. 3, pp. 481489, 2005.

[4] S. Gordon, "Alternative activation of macrophages," Nature Reviews Immunology, vol. 3, pp. 23-35, 2003.

[5] D. M. Mosser, "The many faces of macrophage activation," Journal of Leukocyte Biology, vol. 73, no. 2, pp. 209-212, 2003.

[6] A. Mantovani, A. Sica, S. Sozzani, P. Allavena, A. Vecchi, and M. Locati, "The chemokine system in diverse forms of macrophage activation and polarization," Trends in Immunology, vol. 25, no. 12, pp. 677-686, 2004.

[7] S. Goerdt and C. E. Orfanos, "Other functions, other genes: alternative activation of antigen-presenting cells," Immunity, vol. 10, no. 2, pp. 137-142, 1999.

[8] F. O. Martinez, S. Gordon, M. Locati, and A. Mantovani, “Transcriptional profiling of the human monocyte-to-macrophage differentiation and polarization: new molecules and patterns of gene expression," Journal of Immunology, vol. 177, no. 10, pp. 7303-7311, 2006.

[9] A. Mantovani, T. Schioppa, S. K. Biswas, F. Marchesi, P. Allavena, and A. Sica, "Tumor-associated macrophages and dendritic cells as prototypic type II polarized myeloid populations," Tumori, vol. 89, no. 5, pp. 459-468, 2003.

[10] A. Sica, T. Schioppa, A. Mantovani, and P. Allavena, "Tumourassociated macrophages are a distinct M2 polarised population promoting tumour progression: potential targets of anti-cancer therapy," European Journal of Cancer, vol. 42, no. 6, pp. 717-727, 2006.

[11] C. E. Lewis and J. W. Pollard, "Distinct role of macrophages in different tumor microenvironments," Cancer Research, vol. 66, no. 2, pp. 605-612, 2006.
[12] T. Hagemann, S. K. Biswas, T. Lawrence, A. Sica, and C. E. Lewis, "Regulation of macrophage function in tumors: the multifaceted role of NF- $\kappa$ B," Blood, vol. 113, no. 14, pp. 31393146, 2009.

[13] J. A. Joyce and J. W. Pollard, "Microenvironmental regulation of metastasis," Nature Reviews Cancer, vol. 9, no. 4, pp. 239-252, 2009.

[14] A. Sica, P. Larghi, A. Mancino et al., "Macrophage polarization in tumour progression," Seminars in Cancer Biology, vol. 18, no. 5, pp. 349-355, 2008.

[15] Y. Komohara, M. Jinushi, and M. Takeya, "Clinical significance of macrophage heterogeneity in human malignant tumors," Cancer Science, vol. 105, pp. 1-8, 2014.

[16] Y. Komohara, J. Hirahara, T. Horikawa et al., "AM-3K, an antimacrophage antibody, recognizes CD163, a molecule associated with an anti-inflammatory macrophage phenotype," Journal of Histochemistry and Cytochemistry, vol. 54, no. 7, pp. 763-771, 2006.

[17] Y. Komohara, K. Ohnishi, J. Kuratsu, and M. Takeya, "Possible involvement of the M2 anti-inflammatory macrophage phenotype in growth of human gliomas," Journal of Pathology, vol. 216, no. 1, pp. 15-24, 2008.

[18] Y. Komohara, D. Niino, Y. Saito et al., "Clinical significance of $\mathrm{CD}_{163^{+}}$tumor-associated macrophages in patients with adult T-cell leukemia/lymphoma," Cancer Science, vol. 104, pp. 945951, 2013.

[19] M. A. A. Zaki, N. Wada, J. Ikeda et al., "Prognostic implication of types of tumor-associated macrophages in Hodgkin lymphoma," Virchows Archiv, vol. 459, no. 4, pp. 361-366, 2011.

[20] Y. Komohara, H. Hasita, K. Ohnishi et al., "Macrophage infiltration and its prognostic relevance in clear cell renal cell carcinoma," Cancer Science, vol. 102, no. 7, pp. 1424-1431, 2011.

[21] H. Hasita, Y. Komohara, H. Okabe et al., "Significance of alternatively activated macrophages in patients with intrahepatic cholangiocarcinoma," Cancer Science, vol. 101, no. 8, pp. 1913$1919,2010$.

[22] B. O. Fabriek, M. M. J. Polfliet, R. P. M. Vloet et al., "The macrophage CD163 surface glycoprotein is an erythroblast adhesion receptor," Blood, vol. 109, no. 12, pp. 5223-5229, 2007.

[23] L. C. Bover, M. Cardó-Vila, A. Kuniyasu et al., "A previously unrecognized protein-protein interaction between TWEAK and CD163: potential biological implications," Journal of Immunology, vol. 178, no. 12, pp. 8183-8194, 2007.

[24] M. Kristiansen, J. H. Graversen, C. Jacobsen et al., "Identification of the haemoglobin scavenger receptor," Nature, vol. 409, no. 6817 , pp. 198-201, 2001.

[25] J. G. Calvert, D. E. Slade, S. L. Shields et al., "CD163 expression confers susceptibility to porcine reproductive and respiratory syndrome viruses," Journal of Virology, vol. 81, no. 14, pp. 73717379, 2007.

[26] B. O. Fabriek, R. V. Bruggen, D. M. Deng et al., “The macrophage scavenger receptor CD163 functions as an innate immune sensor for bacteria," Blood, vol. 113, no. 4, pp. 887-892, 2009.

[27] P. Philippidis, J. C. Mason, B. J. Evans et al., "Hemoglobin scavenger receptor CD163 mediates interleukin-10 release and heme oxygenase-1 synthesis: antiinflammatory monocytemacrophage responses in vitro, in resolving skin blisters in vivo, and after cardiopulmonary bypass surgery," Circulation Research, vol. 94, no. 1, pp. 119-126, 2004. 
[28] C. A. Schaer, G. Schoedon, A. Imhof, M. O. Kurrer, and D. J. Schaer, "Constitutive endocytosis of CD163 mediates hemoglobin-heme uptake and determines the noninflammatory and protective transcriptional response of macrophages to hemoglobin," Circulation Research, vol. 99, no. 9, pp. 943-950, 2006.

[29] Y. Fujiwara, Y. Komohara, T. Ikeda, and M. Takeya, "Corosolic acid inhibits glioblastoma cell proliferation by suppressing the activation of signal transducer and activator of transcription-3 and nuclear factor-kappa B in tumor cells and tumor-associated macrophages," Cancer Science, vol. 102, no. 1, pp. 206-211, 2011.

[30] H. Yu, M. Kortylewski, and D. Pardoll, "Crosstalk between cancer and immune cells: role of STAT3 in the tumour microenvironment," Nature Reviews Immunology, vol. 7, no. 1, pp. 41-51, 2007.

[31] A. Matsukawa, K. Takeda, S. Kudo, T. Maeda, M. Kagayama, and S. Akira, "Aberrant inflammation and lethality to septic peritonitis in mice lacking STAT3 in macrophages and neutrophils," Journal of Immunology, vol. 171, no. 11, pp. 6198-6205, 2003.

[32] K. Takeda, B. E. Clausen, T. Kaisho et al., "Enhanced Th1 activity and development of chronic enterocolitis in mice devoid of stat3 in macrophages and neutrophils," Immunity, vol. 10, no. 1, pp. 39-49, 1999.

[33] A. Sica and V. Bronte, "Altered macrophage differentiation and immune dysfunction in tumor development," Journal of Clinical Investigation, vol. 117, no. 5, pp. 1155-1166, 2007.

[34] Y. Xu, R. Ge, J. Du et al., "Corosolic acid induces apoptosis through mitochondrial pathway and caspases activation in human cervix adenocarcinoma HeLa cells," Cancer Letters, vol. 284, no. 2, pp. 229-237, 2009.

[35] M. S. Lee, C. M. Lee, E. Y. Cha et al., "Activation of AMPactivated protein kinase on human gastric cancer cells by apoptosis induced by corosolic acid isolated from Weigela subsessilis," Phytotherapy Research, vol. 24, no. 12, pp. 1857-1861, 2010.

[36] M. S. Lee, E. Y. Cha, P. T. Thuong, J. Y. Kim, M. S. Ahn, and J. Y. Sul, "Down-regulation of human epidermal growth factor receptor $2 /$ neu oncogene by corosolic acid induces cell cycle arrest and apoptosis in NCI-N87 human gastric cancer cells," Biological and Pharmaceutical Bulletin, vol. 33, no. 6, pp. 931937, 2010.

[37] X. Wang, H. Bai, X. Zhang et al., "Inhibitory effect of oleanolic acid on hepatocellular carcinoma via ERK-p53-mediated cell cycle arrest and mitochondrial-dependent apoptosis," Carcinogenesis, vol. 34, pp. 1323-1330, 2013.

[38] B. Chakravarti, R. Maurya, J. A. Siddiqui et al., "In vitro anti-breast cancer activity of ethanolic extract of Wrightia tomentosa: role of pro-apoptotic effects of oleanolic acid and urosolic acid," Journal of Ethnopharmacology, vol. 142, pp. 7279, 2012.

[39] M.-H. Shyu, T.-C. Kao, and G.-C. Yen, "Oleanolic acid and ursolic acid induce apoptosis in HuH7 human hepatocellular carcinoma cells through a mitochondrial-dependent pathway and downregulation of XIAP," Journal of Agricultural and Food Chemistry, vol. 58, no. 10, pp. 6110-6118, 2010.

[40] N. H. Thoennissen, G. B. Iwanski, N. B. Doan et al., "Cucurbitacin $\mathrm{B}$ induces apoptosis by inhibition of the JAK/STAT pathway and potentiates antiproliferative effects of gemcitabine on pancreatic cancer cells," Cancer Research, vol. 69, pp. 5876$5884,2009$.
[41] K. V. Gurova, J. E. Hill, C. Guo et al., "Small molecules that reactivate $\mathrm{p} 53$ in renal cell carcinoma reveal a NF- $\kappa \mathrm{B}$-dependent mechanism of p53 suppression in tumors," Proceedings of the National Academy of Sciences of the United States of America, vol. 102, no. 48, pp. 17448-17453, 2005.

[42] Q. Liu, D. Zhao, X. Chen et al., "Determination of corosolic acid, a natural potential anti-diabetes compound, in rat plasma by high-performance liquid chromatography-mass spectrometry and its application to pharmacokinetic and bioavailability studies," Planta Medica, vol. 77, no. 15, pp. 1707-1711, 2011.

[43] D. I. Gabrilovich, S. Ostrand-Rosenberg, and V. Bronte, "Coordinated regulation of myeloid cells by tumours," Nature Reviews Immunology, vol. 12, no. 4, pp. 253-268, 2012.

[44] T. Condamine and D. I. Gabrilovich, "Molecular mechanisms regulating myeloid-derived suppressor cell differentiation and function," Trends in Immunology, vol. 32, no. 1, pp. 19-25, 2011.

[45] J. W. Pollard, “Tumour-educated macrophages promote tumour progression and metastasis," Nature Reviews Cancer, vol. 4, no. 1, pp. 71-78, 2004.

[46] J. S. Wang, T. N. Ren, and T. Xi, "Ursolic acid induces apoptosis by suppressing the expression of FoxM1 in MCF-7 human breast cancer cells," Medical Oncology, vol. 29, no. 1, pp. 10-15, 2012.

[47] X. Wang, F. Zhang, L. Yang et al., "Ursolic acid inhibits proliferation and induces apoptosis of cancer cells in vitro and in vivo," Journal of Biomedicine and Biotechnology, vol. 2011, Article ID 419343, 8 pages, 2011.

[48] W. Wang, C. Zhao, D. Jou et al., "Ursolic acid inhibits the growth of colon cancer-initiating cells by targeting STAT3," Anticancer Research, vol. 33, pp. 4279-4284, 2013.

[49] P. O. Harmand, R. Duval, C. Delage, and A. Simon, "Ursolic acid induces apoptosis through mitochondrial intrinsic pathway and caspase-3 activation in M4Beu melanoma cells," International Journal of Cancer, vol. 114, no. 1, pp. 1-11, 2005.

[50] N. Gao, S. Cheng, A. Budhraja et al., "Ursolic acid induces apoptosis in human leukaemia cells and exhibits anti-leukaemic activity in nude mice through the PKB pathway," British Journal of Pharmacology, vol. 165, no. 6, pp. 1813-1826, 2012.

[51] K. Liu, L. Guo, L. Miao et al., "Ursolic acid inhibits epithelialmesenchymal transition by suppressing the expression of astrocyte-elevated gene-1 in human nonsmall cell lung cancer A549 cells," Anticancer Drugs, vol. 24, pp. 494-503, 2013.

[52] J. Li, X. Liang, and X. Yang, "Ursolic acid inhibits growth and induces apoptosis in gemcitabine-resistant human pancreatic cancer via the JNK and PI3K/Akt/NF-kappaB pathways," Oncology Reports, vol. 28, pp. 501-510, 2012.

[53] K. Gabrusiewicz, A. Ellert-Miklaszewska, M. Lipko, M. Sielska, M. Frankowska, and B. Kaminska, "Characteristics of the alternative phenotype of microglia/macrophages and its modulation in experimental gliomas," PLoS ONE, vol. 6, no. 8, Article ID e23902, 2011.

[54] G. Germano, R. Frapolli, M. Simone et al., "Antitumor and anti-inflammatory effects of trabectedin on human myxoid liposarcoma cells," Cancer Research, vol. 70, no. 6, pp. 22352244, 2010.

[55] T. L. Rogers and I. Holen, "Tumour macrophages as potential targets of bisphosphonates," Journal of translational medicine, vol. 9, p. 177, 2011.

[56] N. Jing and D. J. Tweardy, "Targeting Stat3 in cancer therapy," Anti-Cancer Drugs, vol. 16, no. 6, pp. 601-607, 2005. 
[57] Y. Fujiwara, Y. Komohara, R. Kudo et al., "Oleanolic acid inhibits macrophage differentiation into the M2 phenotype and glioblastoma cell proliferation by suppressing the activation of STAT3," Oncology Reports, vol. 26, no. 6, pp. 1533-1537, 2011.

[58] H. Horlad, Y. Fujiwara, K. Takemura et al., "Corosolic acid impairs tumor development and lung metastasis by inhibiting the immunosuppressive activity of myeloid-derived suppressor cells," Molecular Nutrition and Food Research, vol. 57, pp. 10461054, 2013. 


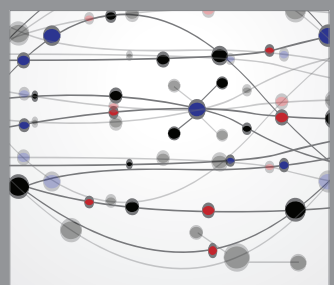

The Scientific World Journal
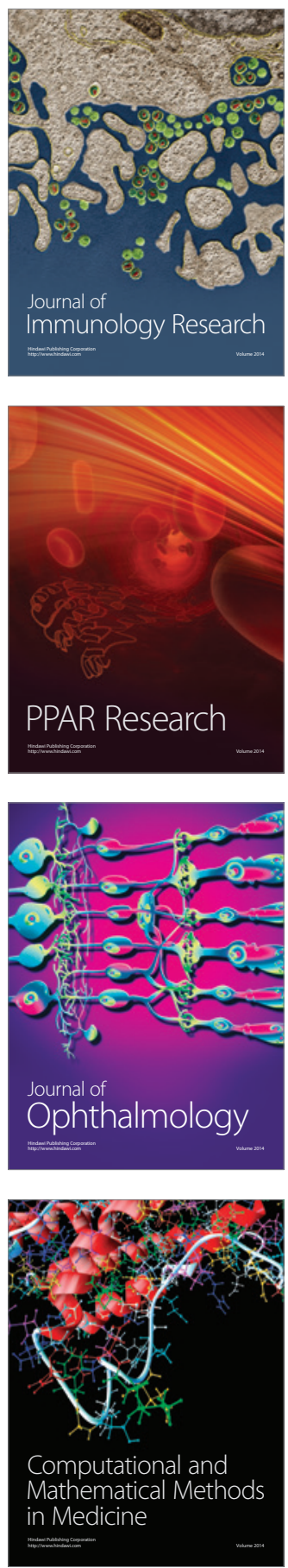

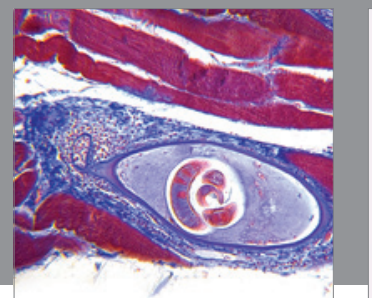

Gastroenterology

Research and Practice
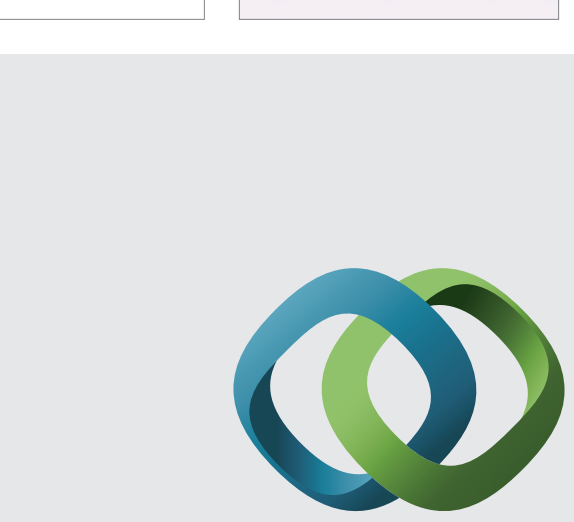

\section{Hindawi}

Submit your manuscripts at

http://www.hindawi.com
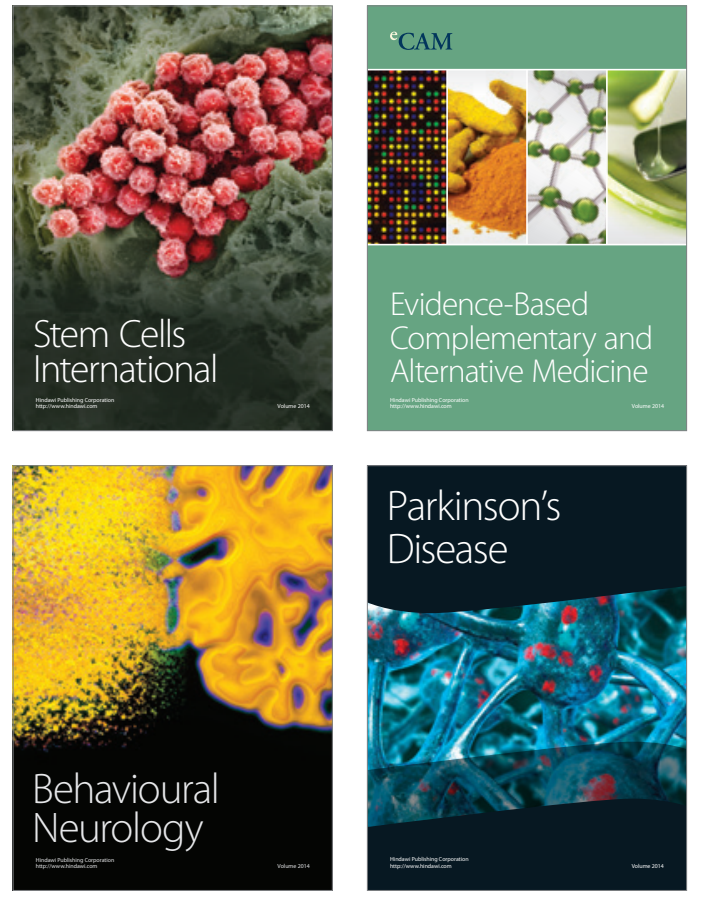
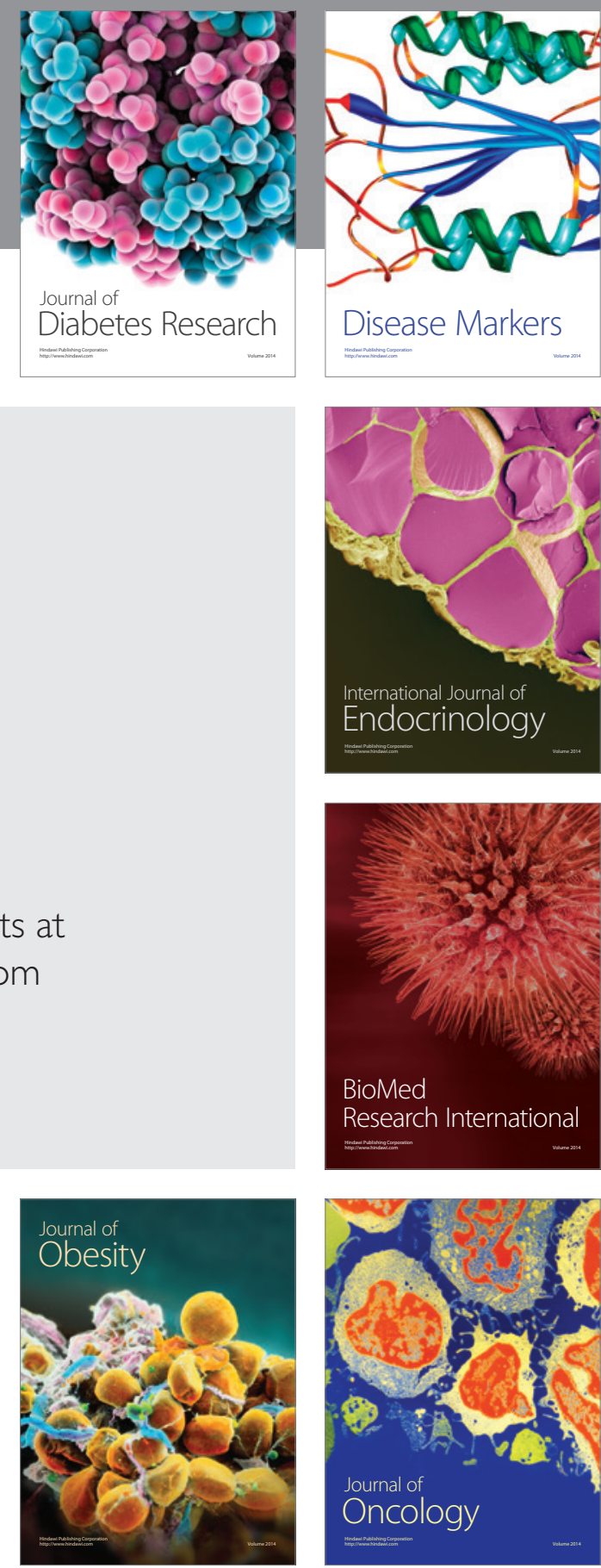

Disease Markers
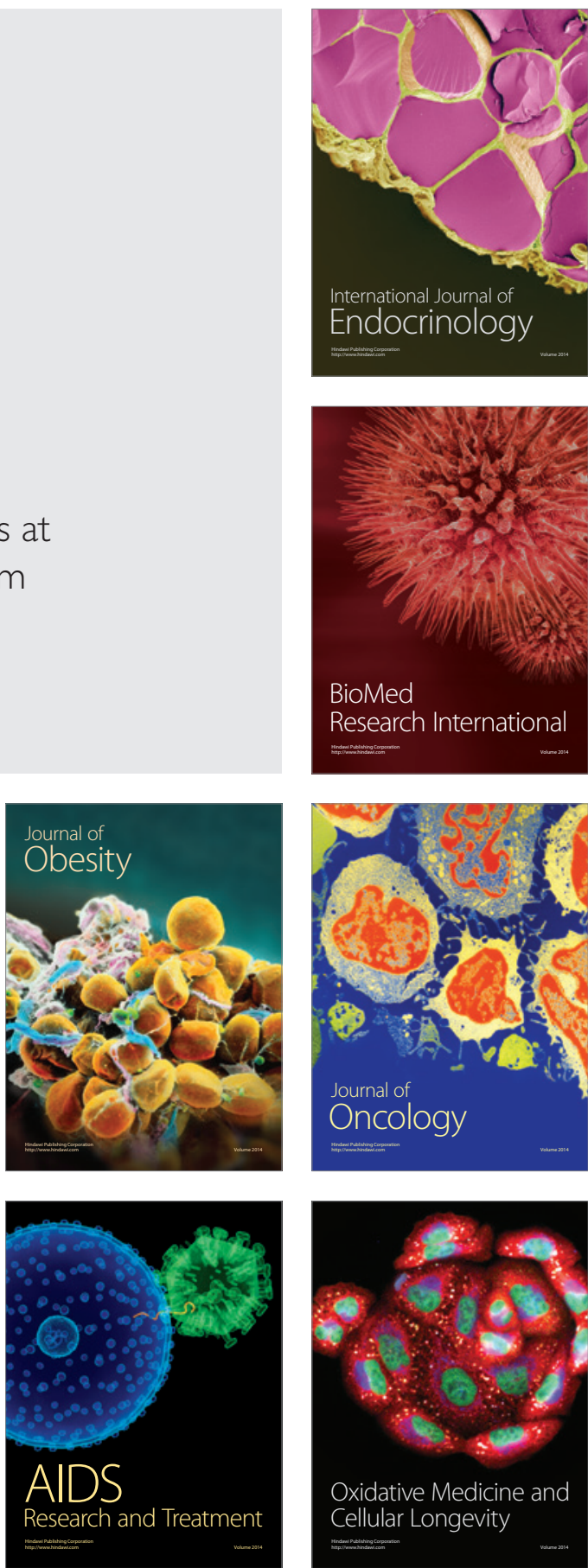